\title{
APLICACIÓN DE TECNOLOGÍAS GEOESPACIALES PARA LA DOCUMENTACIÓN DEL CÍRCULO LÍTICO DE MONTE LOBEIRA, VILANOVA DE AROUSA (PONTEVEDRA $)^{1}$
}

\section{THE APPLICATION OF GEOSPATIAL TECHNOLOGIES FOR THE DOCUMENTATION OF MONTE LOBEIRA'S STONE CIRCLE, VILANOVA DE AROUSA, (PONTEVEDRA)}

\author{
PATRICIA MAÑANA-BORRAZÁS \\ Laboratorio de Patrimonio - CSIC \\ CAMILA GIANOTTI GARCÍA \\ Laboratorio de Patrimonio - CSIC \\ FÉLIX GONZÁLEZ INSUA \\ Laboratorio de Patrimonio - CSIC \\ VICENTE CARAMÉS MOREIRA \\ Museo do Mar de Galicia
}

\begin{abstract}
Resumen
En este trabajo pretendemos realizar una primera aproximación al círculo lítico de Monte Lobeira centrándonos fundamentalmente en las metodologías que se aplicaron en la documentación y registro de los aspectos morfológicos y constructivos del yacimiento.
\end{abstract}

\section{Palabras Clave}

Galicia, Círculo lítico; Topografía de Alta Definición; Láser Escáner 3D; Láser Escáner Terrestre, Metodología de registro arqueológico digital.

\begin{abstract}
In this work, we present a first approach to the stone circle of Monte Lobeira (in the NW of Spain). In this article we primarily focus on the methodologies that were applied in the documentation and register of the morphologic and constructive aspects of the site.

\section{Keywords}

Galicia; Stone circle; High-Definition Survey HDS, Laser Scanner, Terrestrial Laser Scanner TLS, Digital Archaeological Documentation.
\end{abstract}

\footnotetext{
${ }^{1}$ Recibido/Received 22.04. 2010. Aceptado/Accepted 02.06.2010
} 


\section{LOS CÍRCULOS LÍTICOS EN EL NW PENINSULAR.}

Los círculos líticos constituyen una manifestación arqueológica específica de la fachada Atlántica Europea. Formas arquitectónicas como menhires, crómlechs, alineamientos de piedra, timber circles, o ring cairnes, han sido ampliamente documentados y excavados, proporcionando información arqueológica que los ubica a lo largo del cuarto y tercer milenio a.C. en Gran Bretaña, Irlanda y Escocia (Bradley 1998; Bradley et al 2002; Burl 2005; Gibson 2005; Grogan y Roche 2002; Hartwell 2002). También se localizan en la fachada atlántica de la península ibérica, aunque el mayor número de evidencias se concentra en la cornisa cantábrica y al $\mathrm{S}$ del Duero, en Portugal (Blot 1995, 1997; Calado 1997, 2004; Diez 1997; Diez y Ruíz 1995; Monteagudo 2003; Moraza et al 2003; Peñalver 2001, 2005; Silva 1997; Villoch 1998). En Galicia, salvo las estructuras funerarias tumulares que surgen en torno al 4500 a.C., la presencia de otros elementos de carácter megalítico es, hasta el momento, escasa y puntual, siendo muy pocos los trabajos recientes que hablan de ellos (Fábregas y Vilaseco 2003; Monteagudo 2003; Vilaseco 2009; Villoch 1998). No obstante, excavaciones realizadas en los últimos años en Galicia han brindado algunos datos relevantes que permiten avanzar algunos aspectos relacionados con la variabilidad morfológica, funcional y cronológica de este tipo de yacimientos (Bonilla y Fábregas 2009; Cano 2008; Gianotti y Cancela 2005; Fábregas y Bonilla 2008).

Para el caso concreto que nos ocupa, destacamos que el de Monte Lobeira ha sido uno de los primeros círculos líticos señalados en la bibliografía. Estos trabajos de mediados del siglo XIX intentan relacionar testimonios de la Galicia megalítica con los cromlechs y alineamientos de piedra de la fachada atlántica dentro de una corriente romántica y celtista. Entre ellos, como veremos en un apartado posterior, autores como M .Martínez Murguía o L. Saralegui y Medina sitúan menhires en el monte Lobeira.

En trabajos posteriores (Saralegui 1918:54) se citan otros círculos de piedra en el monte Lourado, entre Dumbría y Corcubión, así como en la colina de Faxildre, entre Noia y Santiago. López-Cuevillas y Bouza-Brey (1931:50), en un trabajo posterior, recogen algunos de estos yacimientos y otros nuevos: Monte de San Tegra; en la Pobra de Caramiñal y en Cambados, sobre la ría de Arousa; en el monte Corzán, Xallas; en la colina de Xavilde, Noia; en San Xusto de Corbarcos y en Corme; así como los conocidos de A Mourela, en el alto valle del Eume. En el Inventario de Monumentos Megalíticos de Filgueira Valverde y García Alén (1977), se describen algunos de estos círculos líticos y otros nuevos para la zona de Cambados, Fragas (Campo Lameiro), Torres de Oeste (Catoira), Monte Lobeira (Vilagarcía), Noa- 
1la (Sanxenxo), Santa Trega (A Guarda), A Mourela 1 y 2 (As Pontes), Eira das Meigas en el Monte Neme (Carballo), Monte Corzán (Xallas de Porqueira, Negreira), Lousado (entre Dumbría y Corcubión), Faxilde (Noia), Monte Libureiro (Melide) o Monte das Fachas (A Coruña). No obstante, a pesar de que éstos y otros autores (Obermaier 1923, López-Cuevillas 1959) se han hecho eco de la presencia de estas estructuras citándolas de forma reiterada en diferentes trabajos, coinciden en que ninguno de los yacimientos ha sido objeto de estudios detallados, con excepción del yacimiento de A Mourela, ubicado en la zona de As Pontes (A Coruña). El yacimiento, formado por dos círculos líticos y excavado por F. Maciñeira (1929), se convirtió en el paradigma de este tipo de yacimientos en el NW de la península. Los dos círculos se encuentran compartiendo espacio con una necrópolis tumular, hecho que, junto a otras características organizativas, le llevó a establecer relaciones entre A Mourela y los cromlechs del N y NW de Francia y, especialmente, de las Islas Británicas (Maciñeira 1929).

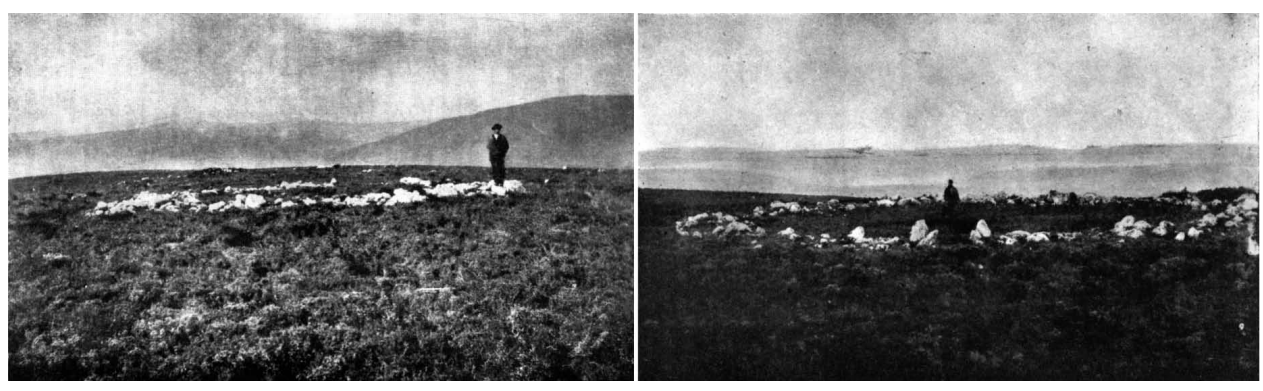

Figura 1. Círculos líticos de A Mourela. Imágenes históricas, tomadas de Maciñeira F., 2002 [1947], (págs. 289 y 297).

Desde este momento álgido de noticias sobre círculos líticos en la bibliografía especializada en Galicia, las referencias publicadas casi desaparecen hasta la última década, en la que se han realizado intervenciones arqueológicas en este tipo de yacimientos. Uno de los círculos de As Pontes, A Mourela 5, fue intervenido durante el 2007 en el contexto de una obra pública (Bonilla y Fábregas 2009; Fábregas y Bonilla 2008). A pesar de las importantes alteraciones documentadas, la excavación permitió identificar una estructura circular de $30 \mathrm{~m}$ de diámetro, delimitada por un anillo de piedra y tierra, y el interior aterraplanado. Al S del círculo se documentó otra estructura de planta cuadrangular conformada por un zócalo de mampostería, con un pavimento de tierra compacta en su interior y un hogar de arcilla rubifactada, identificada como los restos de una cabaña datada entre el s. XV y el XVII d.C. También se documentaron varias fosas, agujeros de poste, 
huellas de roderas, material lítico y cerámico y restos carpológicos, etc. Las dataciones realizadas en la estructura circular y estas fosas abarcan un periodo de uso del sitio entre el s. VIII y el XVI d.C. Con estos datos Fábregas y Bonilla (2009: 257-259) concluyen que tanto la estructura circular como la cabaña son parcialmente coetáneos, interpretando esta última como los restos de un chozo medieval abandonado en época moderna ${ }^{2}$ y el círculo como los restos de un curro donde se refugiaría el ganado.

Otro de los círculos líticos mejor documentados se localizó dentro del yacimiento de Montenegro, península del Morrazo (Moaña, Pontevedra) excavado durante el 2004 en el marco del Programa de corrección de impacto arqueológico del Corredor do Morrazo. La excavación en área permitió documentar un recinto circular megalítico, hasta ese momento no conocido (Gianotti y Cancela 2005; Gianotti et al 2010). El círculo lítico ocupa la parte más alta de un yacimiento más amplio en el que se documentó un asentamiento del Neolítico final y una ocupación medieval. Se trata de un recinto circular de $20 \mathrm{~m}$ de diámetro interno, compuesto por estructuras perimetrales y construcciones internas, una zona de acceso orientada al SE y otras dos posibles zonas de acceso en el lado $\mathrm{N}$ y N$\mathrm{NE}$ que, en conjunto, advierten la complejidad constructiva y la secuencia de uso del mismo.

Desde el punto de vista constructivo, aparece formada la mitad S por sendos anillos pétreos, mientras que hacia el $\mathrm{N}$ está delimitado por una zanja perimetral. En la construcción del anillo, por el lado $\mathrm{W}$, se alteró parte de un afloramiento granítico existente que discurría en sentido N-S, rebajándolo lateralmente hasta dejarlo de $1 \mathrm{~m}$ de espesor, integrándolo como parte de la estructura de cierre. Conectado a esta estructura se dispuso el anillo de grandes piedras hincadas con calzos sobre una zanja de cimentación previa, de forma tal que el cuadrante SW quedó cerrado con ambas estructuras. En el cuadrante SE también se documentó un cierre pétreo pero, a diferencia del anterior, está formada por piedras medianas y pequeñas dispuestas encima del horizonte mineral (Gianotti et al 2010).

En la mitad N, el recinto aparece delimitado por una zanja semicircular de $0,80 \mathrm{~m}$ de ancho, perfil en " $\mathrm{U}$ " y entre 0,30 y $0,40 \mathrm{~m}$ de profundidad. La zanja presenta dos interrupciones, una hacia el NW, donde se une con el afloramiento, y otra hacia el N-NE, que continúa uniéndose con el anillo pétreo del lado $\mathrm{E}$. Ambas interrupciones han sido interpretadas como lugares de acceso secundario al recinto.

${ }^{2}$ Un chozo es una cabaña donde se refugiaban los pastores que cuidaban el ganado en las zonas de monte, lejos de las aldeas. 


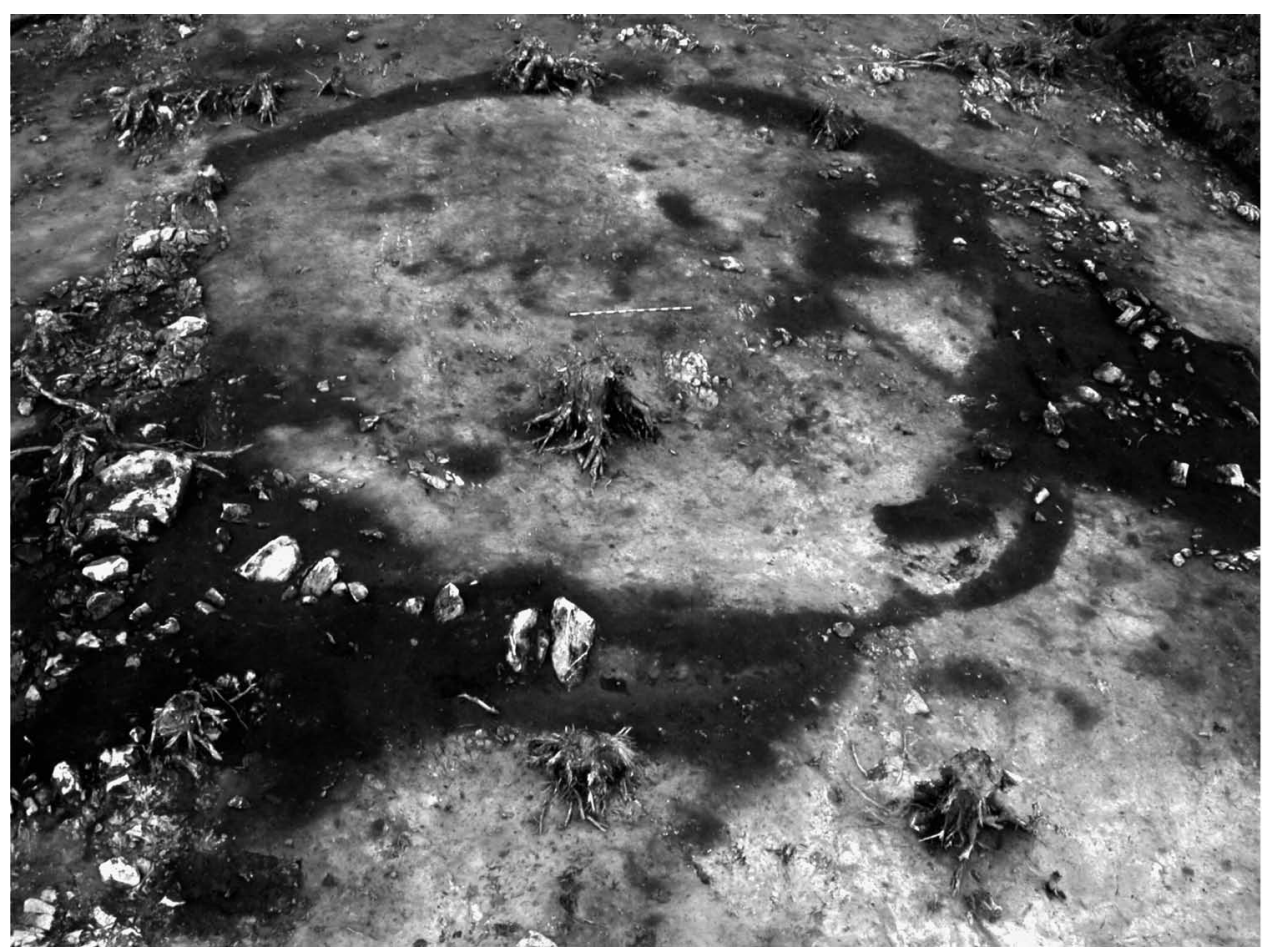

Figura 2. Vista aérea (desde el SW) de la estructura circular localizada en el yacimiento de Montenegro (Moaña, Pontevedera).

En el interior del recinto, en una posición casi central, se excavó una estructura circular, de unos $4 \mathrm{~m}$ de diámetro, formada por improntas de postes, con una zona de acceso orientada al SE remarcada por la presencia de un acceso también definido por agujeros de poste. Además, de manera casi simétrica y adosadas al cierre perimetral, se excavaron dos fondos de cabañas de configuración oval de 3,5 m por 1,5 m. de diámetro. Ambos están formados por zanjas de cimentación e improntas de poste en su base (Gianotti et al 2010). La cabaña situada en el lado interior $\mathrm{W}$ del recinto, de idéntica técnica constructiva a otra localizada en el mismo yacimiento, proporcionó una datación situada en torno al 2790 - 2570 cal BC a 2s con $70.1 \%$ de probabilidad (Ua-23589), totalmente coherente con la datación (2880 - 2570 cal BC a 2 s con $95.4 \%$ de probabilidad, Ua-23591) obtenida de la cabaña situada a media ladera (Gianotti et al 2010).

La mayor parte de la cultura material recuperada procede del recinto circular. En el sitio se recuperaron cerca de 2.300 piezas cerámicas, 1.032 piezas líticas, además 
de ocre, adobe y fragmentos de hierro procedentes del área con la ocupación medieval (Gianotti et al 2010).

De la información disponible en algunas de las publicaciones y los trabajos realizados por nosotros mismos destacan algunos aspectos de interés que permiten detectar algunas similitudes y diferencias, tanto en aspectos formales como locacionales para estos yacimientos.

\section{EL CÍRCULO LÍTICO DE MONTE LOBEIRA}

El yacimiento arqueológico se localiza en el W de Galicia, en el Valle del Salnés, delimitado al N por la Ría de Arousa, al S por la Ría de Pontevedra y al E por la depresión meridiana. Concretamente está situado en el monte conocido como Monte Lobeira, caracterizado como una formación montañosa que delimita la cuenca del río Umia al N y W y que se encuentra aproximadamente a unos $4 \mathrm{~km}$ de la orilla SE de la Ría de Arousa. Alcanza los 292 m.s.n.m. de altitud y está conformado por un sustrato geológico compuesto íntegramente de granodiorita.

El círculo lítico está emplazado a una altitud de 191,70 m.s.n.m., situado en la dorsal meridional del Monte Lobeira. Ocupa uno de los últimos rellanos existentes antes de que el relieve más alto dé paso a una amplia zona de vaguada donde se encuentran las aldeas más cercanas.

Los límites $\mathrm{W}$ y $\mathrm{S}$ de este rellano los forma la empinada ladera del propio monte que desciende hacia la zona de valle. Hacia el E la pendiente es menor, abriéndose el terreno a un pequeño collado que finalizará, otra vez, con una caída brusca de la ladera E del monte. Sin embargo, la delimitación hacia el N difiere bastante de las anteriores. En este punto, el rellano está delimitado por una serie de espolones y oteros entre los que se divisa, al NE, la cima del Monte Lobeira, situada a 292 m.s.n.m. y que, formada por toda una serie de grandes afloramientos rocosos, constituye, sin duda, el elemento natural más destacado en el paisaje de todo el entorno. La presencia de afloramientos rocosos destacados y muy visibles en la cima de Monte Lobeira, permiten identificarlos como un monumento salvaje tal y como éste ha sido definido por F. Criado-Boado (1993), ya que constituyen el elemento natural más conspicuo, lo que contribuye a resaltar la visibilidad espacial y la localización de la construcción circular. 


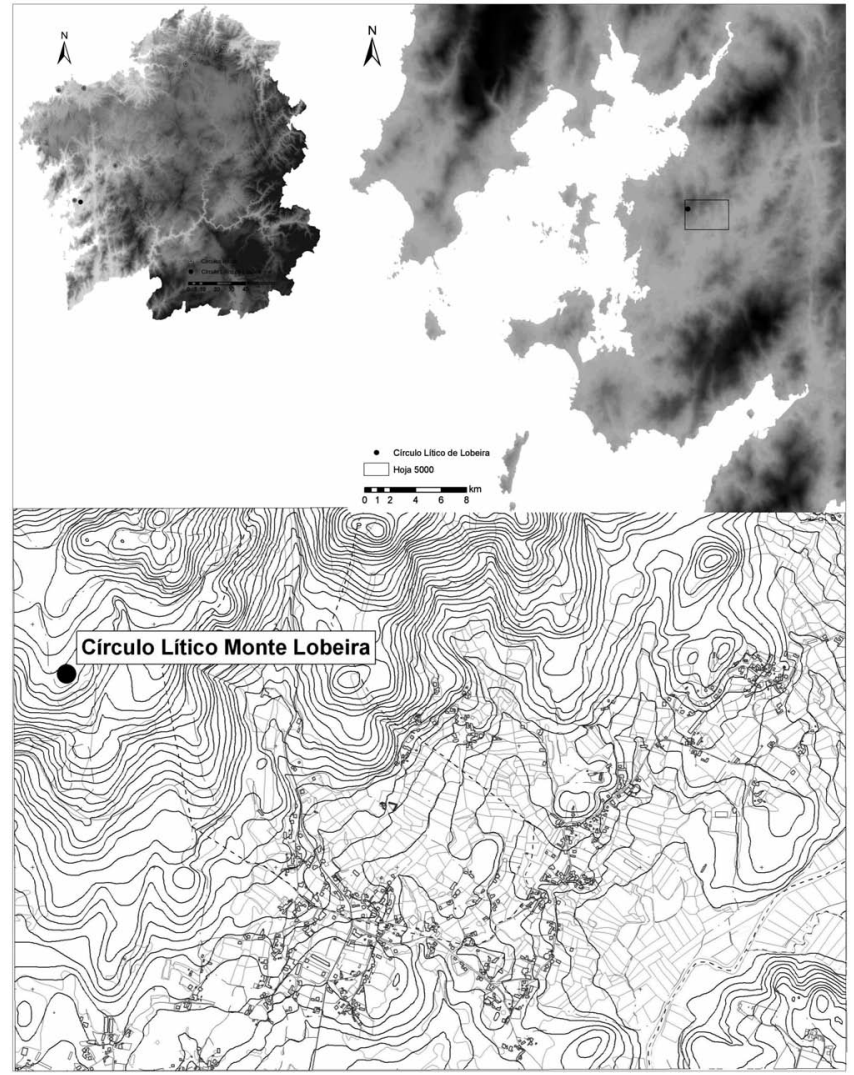

Figura 3. Ubicación geográfica y contexto topográfico del círculo lítico de Monte Lobeira. Modelo digital de elevaciones (30 m) y cartografía escala 1:5000 (hoja 152/63).
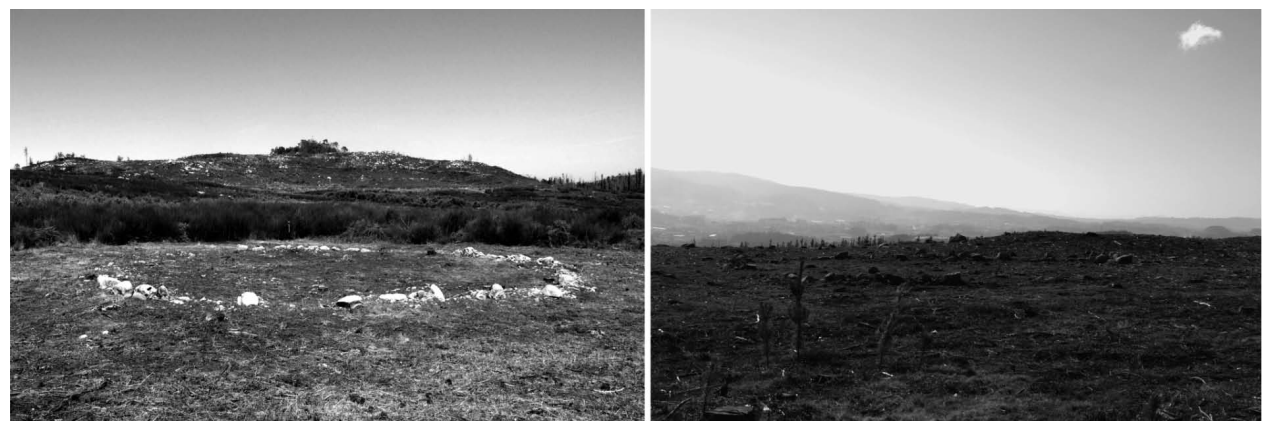

Figura 4. Imagen izquierda: vista del círculo (desde el SW) con afloramientos que limitan la visibilidad desde el círculo hacia el NE (cima del Monte Lobeira). Imagen derecha: vista del círculo desde el NE con visibilidad extendida sobre Monte Castrove y Val do Salnés. 
A pesar de que la estructura circular no se encuentra en una de las mayores altitudes del Monte Lobeira, la visibilidad desde el círculo es muy amplia. El análisis de la visibilidad desde el yacimiento permite observar una dualidad en las condiciones de visibilidad, pudiéndose establecer un eje en sentido SW - NE con dos mitades de características visuales opuestas:

Al S de este eje, la visibilidad alcanza su mayor amplitud llegando hasta la costa, con un dominio visual sobre las tres islas situadas en la entrada de las tres Rías Baixas gallegas, es decir: la isla de Sálvora, las islas de Ons y las islas Cíes, cabezas de las rías de Arousa, Pontevedra y Vigo respectivamente. También hacia el S, aunque hacia el interior, la visibilidad es considerable, alcanzando las estribaciones NW de la Serra do Testeiro y algunos puntos de la ladera W de la Serra do Suido. En una distancia más próxima hacia esta mitad S, destaca el dominio visual sobre la ladera N del Monte Castrove (613 m.s.n.m.), la península de O Grove; una gran parte del valle del Salnés, controlando el curso del río Umia; así como el acceso a este valle desde la depresión meridiana, depresión que atraviesa Galicia prácticamente de $\mathrm{N}$ a S. En cambio, en el ámbito inmediato al círculo, la visibilidad se reduce a unas decenas de metros, cayendo la pendiente a pocos metros al $\mathrm{S}$ del emplazamiento del yacimiento.

Hacia la mitad $\mathrm{N}$ del eje anteriormente establecido, la visibilidad se reduce al entorno inmediato, constreñido por las laderas y cimas del propio Monte Lobeira a modo de circo natural. En el horizonte, la visibilidad está limitada por dos espolones (más cercanos) en el centro de los cuales sobresale el afloramiento rocoso que conforma el punto más alto del Monte Lobeira (más alejado) y que, como dijimos antes, constituye el elemento natural más destacado de todo el entorno.

Creemos que la elección concreta del emplazamiento se realizó en relación con este juego visual entre los elementos naturales, siendo el Monte Lobeira un referente natural que muy probablemente también ejerció una gran influencia en la elección del emplazamiento del sitio, como lo atestigua la distribución concreta del círculo y de los dos túmulos inmediatos, alineados los tres en sentido NE-SW y con el propio Monte Lobeira, que se encuentra al NE de estos yacimientos. 


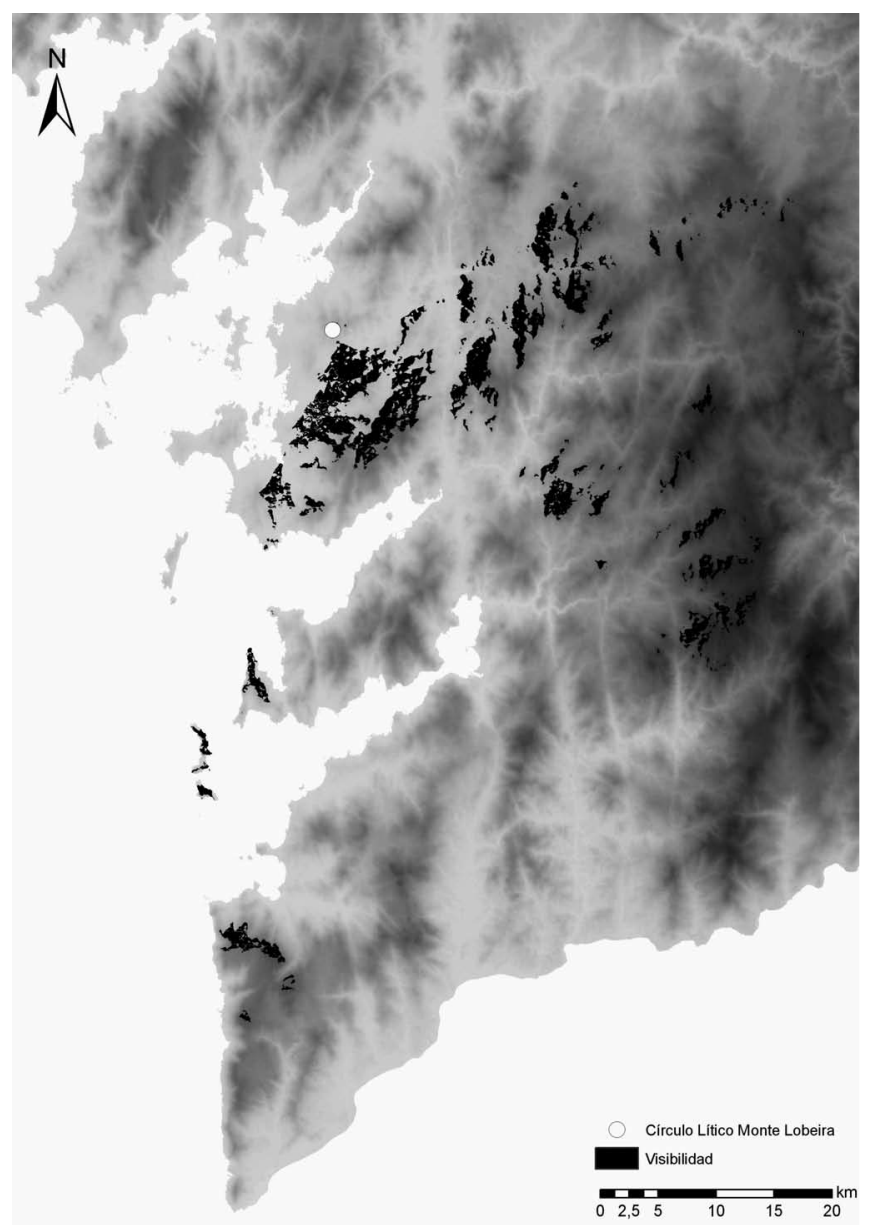

Figura 5. Modelo digital de elevaciones (resolución 30m) con la ubicación del círculo lítico de Monte Lobeira y el análisis de su cuenca visual.

\section{CONTEXTO ARQUEOLÓGICO}

En el entorno del círculo lítico se emplazan dos túmulos megalíticos recogidos en el Inventario de Yacimientos Arqueológicos de la Dirección Xeral de Patrimonio Cultural (Consellería de Cultura e Turismo, Xunta de Galicia) desde el año 1991 con la clave GA36061003. El más cercano al círculo lítico es el Túmulo I, que tiene unas dimensiones en el eje N-S de 17,40 $\mathrm{m}$ y de 19,60 m en el E-W, y que posee un cono de violación central de 5,9 m por $11 \mathrm{~m}$. La profundidad de la violación es 
de $0,30 \mathrm{~m}$ y la altura del túmulo de $0,70 \mathrm{~m}$. Presenta coraza y dos ortostatos. El Túmulo II se sitúa a $26 \mathrm{~m}$ al E del túmulo I. Tiene un diámetro de 17,60 m en el eje $\mathrm{N}-\mathrm{S}$ por 16,60 m en el E-W. La altura del túmulo es de 0,90 m y el cono de violación central tiene unas dimensiones de 5,30 x 6,40 m, siendo la profundidad de la misma de 0,40 m. En la actualidad, en ausencia de datos concretos sobre el momento constructivo del círculo lítico y de una contextualización cronológica de los túmulos megalíticos adyacentes, se nos antoja temerario establecer entre el conjunto algo más que la constatación de esta proximidad.

Muy próximo al círculo lítico, en un rellano en la ladera SW del monte de Lobeira, en las coordenadas X: 518967 e Y: 4712102, en la caja y taludes de un camino de tierra que lleva al mirador del Faro das Lúas, se localiza una importante dispersión de material cerámico de la edad del bronce. Son fragmentos de pastas groseras con desgrasantes de grueso calibre, formas cóncavas, superficies alisadas y factura manual. En este contexto, en el año 2000 se localizó un hacha de piedra pulida. Materiales cerámicos con las mismas características tipológicas se han documentado también en los cortes de un camino que corta transversalmente la hombrera S del monte de Lobeira (X: 519465, Y: 4712104) y en las proximidades del aparcamiento situado en la falda S de la fortaleza medieval (X: 519578, Y: 4712578). La concentración de materiales cerámicos más alejada del circulo lítico se emplaza en una pequeña vaguada entre el Monte de Renza y el Monte Lobeira (X: 518800 e Y: 4712515). Es también la zona que ofrece una menor densidad de hallazgos.

El yacimiento más emblemático de la zona y que da nombre al monte es, sin lugar a dudas, la fortaleza medieval de Lobeira. Las primeras referencias a la existencia de este recinto defensivo son del siglo X, en tiempos de Alfonso IV. Su fin como enclave militar se deberá a la revuelta Irmandiña (1467-1469). En el siglo XVII sus piedras servirán para edificar el Pazo do Rial (Vilanova de Arousa). La fortaleza será incorporada al catálogo de yacimientos de la Xunta de Galicia en el año 1991, con la clave de referencia GA36061012. Dentro del recinto de la fortaleza se emplaza también un petroglifo de adscripción medieval (tablero de juegos).

\section{HISTORIOGRAFÍA Y FOLCLORE DEL SITIO.}

Las referencias al círculo de los autores que podemos denominar clásicos son un tanto confusas. Será Martínez Murguía, en su famosa Historia de Galicia, el primero en hacer referencia a la posible existencia de menhires en el Monte Lobeira, información que le fue proporcionada por "persona inteligente en esta clase de estu- 
dios" (Martínez Murguía 1901:585). Este autor, en esta misma obra, reconoce que no se tiene constancia en todo Galicia de "un solo menhir notable, ni un alineamiento, ni un cromlech, verdaderamente caracterizado". Además, Murguía entiende los cromlechs como menhires a marcada distancia unos de otros, morfología que no se corresponde con la del círculo lítico objeto de análisis en este trabajo. Sin embargo, pese a su definición, acepta como cromlechs (Martínez Murgía 1901:585 y ss.) los descubiertos por F. Maciñeira en As Pontes de García Rodríguez, estructuras similares, salvando las distancias, a la estructura que ahora nos ocupa.

L. de Saralegui y Medina (1867:179) también hace referencia a los monumentos megalíticos hallados en el Monte Lobeira, destacando que "Galicia tiene (...) muchos y curiosos menhires en el Monte Lobeira". Sin embargo, no atestigua en dicho monte la existencia de lo que él denomina Kroumleac'h, menhires que "en vez de hallarse colocados en línea recta, constituyen un círculo o una elipse" (Saralegui 1867:185)

M. de Saralegui y Medina (1918:53-67) hace la misma distinción. Diferencia entre carneillou, menhires clavados con desconcierto, de los que existen, según él, ejemplos en el Monte Lobeira (Saralegui 1918:54); y cromlechs, "piedras en pie, grandes rocas o simples cantos, que en lugar de estar agrupados en perfecta alineación, lo están formando circulo", de los que existen pocos casos en España.

Será haciendo referencia a Murguía cuando F. López Cuevillas (1959:66-69) nos señale la existencia de "un grupo de menhires situado en el Monte Lobeira". Por otro lado, identifica como únicos los círculos líticos de A Mourela, que, recordemos, poseen una morfología bastante similar a la estructura que estamos analizando, además de presentar, también, una vecindad próxima a túmulos.

Este carácter único de los círculos líticos de A Mourela también lo recoge F. Maciñeira (1929: 217-218).

La primera referencia clara a un cromlech en el Monte Lobeira la encontramos en la Carta arqueológica de la provincia de Pontevedra, elaborada por J. Filgueira Valverde y A. García Alén (1956). En ella, se hace referencia a una conferencia pronunciada por H. Obermaier en la Universidad de Santiago de Compostela, recogida en las páginas del Diario de Santiago del 29 de octubre de 1922. Aunque no hemos podido tener acceso a la noticia ${ }^{3}$, las conferencias pronunciadas por Obermaier fueron recogidas al año siguiente en el Boletín Arqueológico de la Comisión Provincial de Monumentos Históricos y Artísticos de Ourense bajo el título Impresiones de un viaje prehistórico por Galicia. En su trabajo, Obermaier no hace refe-

${ }^{3}$ El Diario de Santiago dejó de editarse en 1878, siendo continuado por la Gaceta de Galicia, que dejó de editarse en 1918. 
rencia a ninguna construcción en el Monte Lobeira, sino a "curiosas construcciones cerca de la Puebla y de Cambados (ría de Arosa)", siguiendo la obra de Murguía (Obermaier 1923:14).

Años más tarde, J. Filgueira Valverde y A. García Alén (1977:130) volverán a recoger la existencia de un círculo lítico en el Monte Lobeira, haciendo referencia a una bibliografía que hemos analizado aquí íntegramente.

El único autor que rechaza específicamente la existencia de un cromlech en el monte Lobeira es V. Viqueira (1960: 11), en un estudio sobre la fortaleza medieval que se encuentra a un escaso kilómetro del círculo lítico. Sin embargo, el concepto de cromlech que utiliza Viqueira es el de menhires separados entre si, formando un gran espacio interno, ya que argumenta que el "cromlech, cuya existencia se da por descontada en Lobeira, nos parece una ofuscación que confunde el conjunto circular de menhires con la cerca de un pinar cualquiera" (Viqueira 1960:11).

En conclusión, las referencias bibliográficas que se hacen eco de la existencia de un círculo lítico en el Monte Lobeira son imprecisas, siempre indirectas y confusas. Por lo tanto, podemos afirmar que no será hasta 1991 cuando, en el marco de la realización del primer inventario de yacimientos del Ayuntamiento de Vilanova de Arousa $^{4}$, tengamos la primera referencia precisa a la estructura circular que nos ocupa.

Otro capítulo que nos debe ocupar es la interpretación que los vecinos de la parroquia hacen del círculo. En el imaginario popular están presentes, en esta zona, los "mouros", los seres míticos protagonistas de leyendas existentes en todo el conjunto del NW peninsular. Esta presencia de "mouros" no nos debe sorprender, ya que, recordemos, el círculo posee una vecindad inmediata a dos túmulos.

Más interesante nos parece otro tipo de información que nos aportaron algunos vecinos: la interpretación del círculo como una "eira de mallar". La "eira" es el lugar donde se lleva a cabo la malla de cereales como el trigo, la cebada, el centeno, etc., que tiene como finalidad la separación del grano, aunque también puede cumplir otras finalidades como secar los granos de maíz o las habas, desgranar las castañas, etc. (Bas 1997:284-287; Bas 2002:108-111; Mariño 2000:53-57). Sin embargo, existen algunos factores que nos inclinan a rechazar esta hipótesis interpretativa. En primer lugar, su situación. El círculo se encuentra en una zona de arbolado, estando próximas, aunque de manera marginal, algunas zonas de monte bajo y matorral. Las zonas dedicadas a cultivo ocupan el valle, siempre lejos de la zona de estudio. En segundo lugar, la "eira" suele formar un conjunto con el hórreo y con otras cons-

${ }^{4}$ Realizado por V. Carames Moreira y Manuel Alfonsín Soliño. 
trucciones junto a la casa (Bas 1997:284; Bas 2002:108). No suele encontrarse completamente aislada, como es el caso de la estructura que estamos analizando.

Por último, a pesar de que muchas "eiras" son de tierra y algunas se encuentran cercadas por un pequeño muro de unos 20 a $80 \mathrm{~cm}$. (Mariño 2000:53), la superficie siempre debe ser horizontal y lisa (Bas 1997:284; Mariño 2000:53), condición que no parece cumplirse en nuestro caso, ya que nos encontramos ante una superficie irregular con una relativa abundancia de piedras de pequeño y mediano tamaño.

En una reciente intervención arqueológica realizada en uno de los círculos líticos de A Mourela se identifica dicho círculo como un curro para el ganado (Bonilla y Fábregas 2009; Fábregas y Bonilla 2008:188), es decir, una construcción popular e histórica relacionada con el pastoreo. Sin embargo, no parece que esta interpretación pueda extrapolarse al círculo del Monte Lobeira, ya que estos curros suelen estar formados por muros bastante altos (Bas 1997:347; Bas 2002:148) que, a nuestro entender, la base del círculo no sería capaz de soportar. De todas formas, somos conscientes de que para sostener tal afirmación sería imprescindible un estudio arqueológico y arquitectónico pormenorizado de la estructura circular.

Además, estos curros necesitan una entrada por la que se hace pesar el ganado (Bas 1997:347), entrada que no parece existir en la estructura que nosotros analizamos, ya que la posible interrupción del círculo que detectamos al NE nos parece insuficiente para cumplir una función de entrada del ganado al mismo. Una futura intervención arqueológica en el círculo para dilucidar aspectos como éste se revela imprescindible.

\section{PROCEDIMIENTOS METODOLÓGICOS PARA EL REGISTRO Y CARACTERIZACIÓN ARQUEOLÓGICA DEL CÍRCULO LÍTICO}

En el transcurso del desarrollo de la disciplina arqueológica, la forma de aproximación, tratamiento y análisis de las entidades arqueológicas ha variado significativamente. A lo largo de un siglo hemos visto cómo la consideración inicial de la excavación arqueológica como único método de documentación y caracterización de un yacimiento ha cambiado en la actualidad. En las últimas décadas hemos asistido a la incorporación y desarrollo de un sinfín de métodos y técnicas no destructivas procedentes de otras disciplinas que han permitido acceder a algunos aspectos relativos a la naturaleza de los objetos y/o sitios arqueológicos sin tener que intervenir en ellos. En particular, la incorporación de tecnologías geoespaciales ha desembocado en nuevas y mejores formas de detección, documentación e incluso análisis de los yacimientos arqueológicos. 
Una de las primeras técnicas aplicada de forma sistemática con excelentes resultados a la detección y análisis de sitios arqueológicos fue la interpretación de fotografías aéreas (Orejas 1995). Otras formas de sensoramiento remoto, como la teledetección y el empleo de técnicas geofísicas han logrado hondo calado como estrategias de prospección indirecta. El empleo de sistemas GPS, imágenes de satélite (Landsat, Spot), tecnologías basadas en radares, o tecnologías LIDAR (Laser Imaging Detection and Ranging) ha generado cambios sustanciales en las formas de adquisición y tratamiento digital relativos a todo tipo de superficies. Todo ello, sumado al uso cada vez más extendido de los SIG, está demandando nuevos procedimientos estandarizados de registro de información arqueológica.

Pero además de aumentar el tipo de tecnologías de localización remota y posicionamiento global, también se han visto incrementadas las técnicas de registro detallado de los elementos y sitios arqueológicos, que buscan realizar una documentación precisa de los distintos elementos que constituyen el objeto de estudio para obtener unos resultados cada vez más fiables y ajustados a la realidad.

Los métodos más habituales de registro en detalle son el dibujo arqueológico realizado a escala y con mediciones a mano, el levantamiento mediante instrumentos topográficos, la fotogrametría y el Láser Escáner Terrestre. Uno de los productos más habituales de estos trabajos de levantamientos topográficos con distintas técnicas es la obtención de representaciones en 2D del objeto de estudio (plantas, secciones, alzados). Pero, como cada vez es más habitual ver en los trabajos arqueológicos, la tendencia actual se orienta a obtener la información necesaria para representar este sitio o elemento arqueológico en $3 \mathrm{D}$, y con ello, obtener un modelo 3D que represente gráficamente tanto su geometría, su volumen, como su aspecto en sus distintas caras. En este sentido, en los últimos años se ha incorporado como técnica de registro en el patrimonio cultural la captura de nubes de puntos por medio de láser escáner 3D o Láser Escáner Terrestre (p.e., Arias et al 2005; Lambers et al 2007; Lichti et al 2008; Mañana et al 2009; Marambío y García 2006; Monserrat y Crosseto 2008; Schulz y Ingensand 2005; Yastikli 2007).

Pero la documentación de un elemento patrimonial no consiste únicamente en la toma de datos in situ, sino también que involucra los procedimientos necesarios para procesar esta información, su representación posterior así como el archivo de los datos imprescindibles para representar la forma, volumen y tamaño del elemento documentado en un determinado momento de vida del mismo, y que además sea una información coherente y comparable con datos tomados en otros momentos o con otros sistemas de registro. 


\section{PROCESO DE TRABAJO}

En este apartado presentamos la secuencia de procedimientos y las técnicas empleadas para realizar la documentación del círculo lítico, centrándonos especialmente en el método más novedoso utilizado: el levantamiento topográfico de alta definición realizado con Láser Escáner Terrestre.

Este yacimiento se encuentra en una zona de monte explotado por la Mancomunidad de Montes de András, que es propietaria de los terrenos. Hasta el año 2006, el área se encontraba cubierta por monte alto de eucaliptos, que fue afectado por un incendio en el verano de ese año. Tras la extracción de la madera, la zona donde se encuentran el círculo y los túmulos más próximos se encuentra a monte bajo, sin haberse realizado hasta el momento una nueva plantación.

En el momento en el que realizamos este trabajo (2008), la Mancomunidad de Montes había realizado la limpieza de parte de esta área, por lo que el yacimiento y su entorno más inmediato se encontraban totalmente despejados y se podía percibir sin problemas la extensión y características del sitio.

\section{Fotografía}

Parte del proceso de documentación se realizó a través de fotografía digital. Se realizaron fotografías generales del círculo y otras de detalle de la estructura pétrea que lo delimita con la finalidad de documentar los materiales empleados y aspectos constructivos del mismo. También se documentó el entorno en diferentes momentos a medida que iban avanzando los trabajos de limpieza del monte, ya que excepcionalmente se encontraba libre de vegetación gracias al programa de limpieza de la comunidad de montes. Este aspecto ha permitido obtener una documentación de mayor calidad que la que habíamos logrado previamente, con el círculo y el área cubierta por vegetación arbustiva y arbórea.

\section{GPS}

La primera fase de documentación geoespacial planteada se realizó a través del levantamiento con GPS centimétrico con corrección diferencial en tiempo real. Este tipo de GPS permite el registro de datos con precisión centimétrica y por lo tanto un registro ágil, preciso y con gran detalle. Con él hemos obtenido un levantamiento con la posición global de los elementos, documentado en detalle el contorno de los tres yacimientos que se encuentran en el sitio, y además, en el caso del círculo, el contorno interior y exterior. 


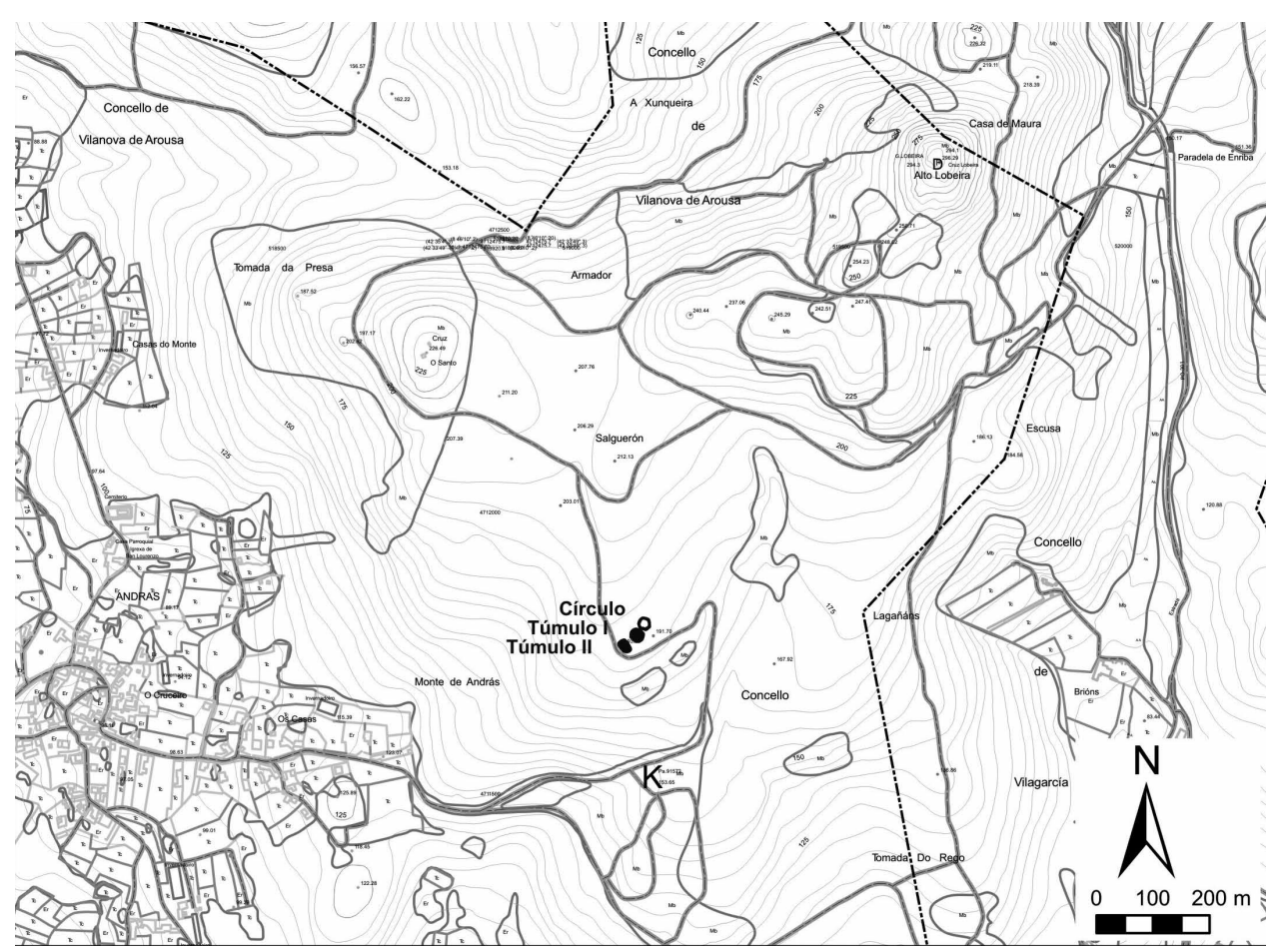

Figura 6. Plano de detalle con el levantamiento realizado con GPS.

\section{Documentación geométrica con Láser Escáner 3D}

El Láser Escáner 3D permite una captura de información rápida, detallada y precisa de una superficie o volumen, siendo un método de medición no-intrusivo basado en la tecnología de escáner con láser pulsado. Este instrumento también se denomina habitualmente como Láser Escáner Terrestre (Terrestrial Laser Scanning, TLS) o LIDAR terrestre, en contraposición con otras herramientas de tecnología análoga como el cada vez más extendido LIDAR que opera sobre una plataforma aerotransportada y que posibilita la telemetría y teledetección.

El modelo de Láser Escáner Terrestre empleado (un HDS3000 de Leica) tiene un aspecto similar a una Estación Total, aunque de mayores dimensiones y peso, posicionándose por lo general sobre un trípode ${ }^{5}$. El sistema de medición del ins-

5 Uno de nosotros ha publicado una descripción con mayor detalle sobre este instrumento y su problemática, así como la experiencia de la documentación de otros elementos patrimoniales en Galicia (Mañana-Borrazás et al 2009). Además, en Boheler et al 2003 se presenta un estudio sobre la problemática y condiciones del registro con Láser Escáner Terrestre y una comparativa entre varios modelos comerciales. 
trumento es el láser de impulsos (pulsed time-of-flight), en el que se calcula la distancia a partir del tiempo (de vuelo) que tarda el retorno de la señal emitida por el láser. Permite una captura de datos milimétrica, con una densidad de un máximo de un punto cada $2 \mathrm{~mm}$, siendo capaz de realizar la toma de datos posicionado en un rango entre $1 \mathrm{~m}$ hasta los 250-300 $\mathrm{m}$ de distancia al elemento a registrar. El láser empleado es tipo 3R (IEC 60825-1), color verde y visible, un tipo de láser que no afecta ni altera las superficies que registra, incluyendo las más delicadas como pueden ser las pintadas, aunque para el ser humano existe riesgo de daño en los ojos si se mira directamente al láser emitiéndose desde el aparato.

Este Láser Escáner realiza un barrido de una superficie captando miles de puntos por segundo con un haz de láser en abanico. El resultado es una nube de puntos $3 \mathrm{D}$ compuesta por miles y hasta millones de mediciones, con la que se obtiene la digitalización de una superficie a partir de puntos individuales. La visualización de esta nube de puntos alcanza gran realismo ya que este modelo de Láser Escáner, que incorpora una cámara fotográfica, relaciona directamente el punto tridimensional medido con el color del píxel de la fotografía de referencia, lo que permite ver la nube de puntos como si fuera un modelo digital del elemento registrado, aunque lo que vemos en realidad son puntos y no una superficie.

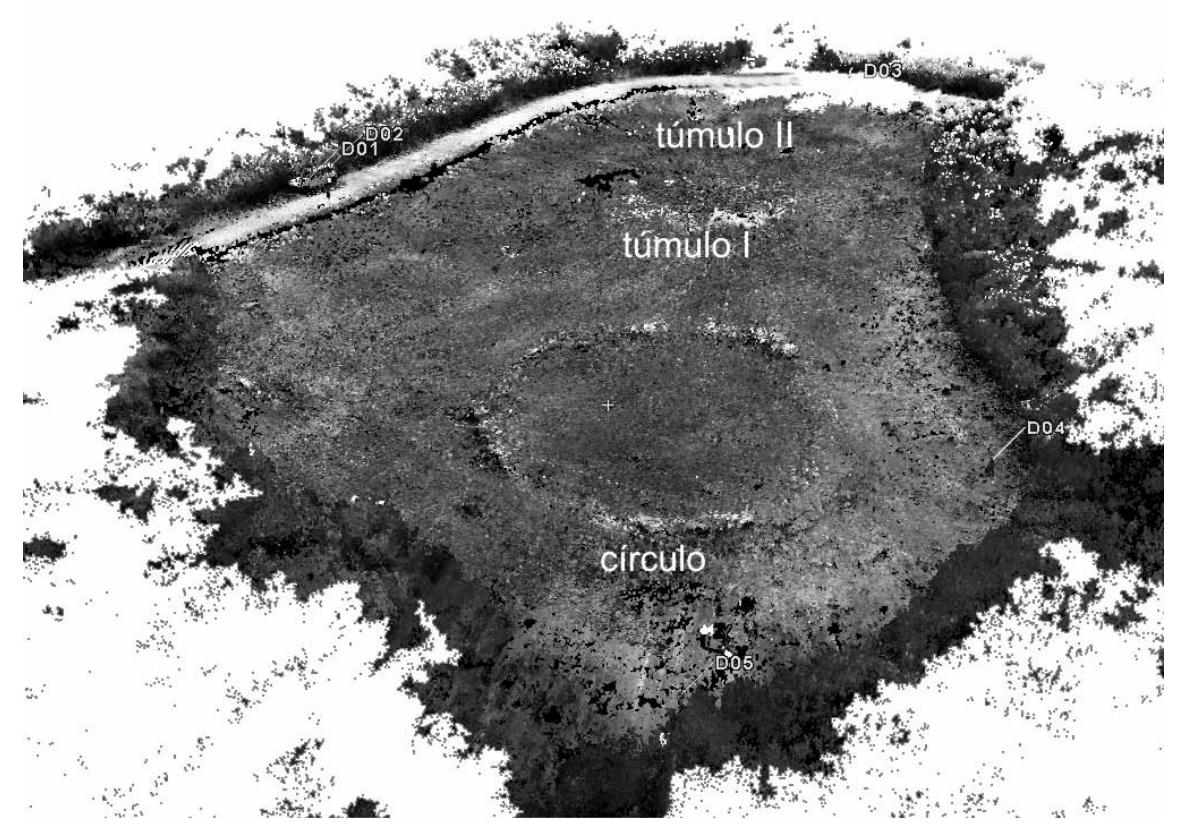

Figura 7. Nube de puntos desde las tres posiciones unidas 
En este barrido se digitaliza cualquier elemento que se encuentre en el área de captura, por lo que registra vegetación, elementos móviles que interfieran en ese preciso momento, etc. También supone que sólo captura lo que se encuentra en el campo de visión del Láser Escáner, por lo que, para obtener un volumen por varias caras, es necesario posicionarlo en otro lugar desde donde sea visible la cara que resta por digitalizar. También por esto, para lograr un registro óptimo, lo ideal es tener una superficie limpia de vegetación, como fue nuestro caso.

Para obtener el registro completo del círculo colocamos el escáner en 3 posiciones en torno al círculo, obteniendo una nube de casi 38 millones de puntos, resultado de unas 7,5 h de toma de datos en campo. Este registro abarca tanto el propio círculo como su entorno inmediato, alcanzando un área de unos $200 \mathrm{~m}$ de diámetro. En el momento en el que realizamos este levantamiento, salvo la parte más próxima al yacimiento, los túmulos y la carretera, el resto de la zona estaba cubierta por monte bajo, por lo que no tiene gran valor a nivel de analítica de la superficie del terreno. En ningún caso hemos precisado intervenir sobre el yacimiento, ya que el tipo de sistema de registro empleado no necesita que el elemento sea manipulado, ni siquiera colocando un bastón o regla encima, por lo que la integridad del yacimiento está garantizada, siendo incluso recomendable para documentar elementos inaccesibles o que son poco estables, incluso si es peligroso aproximarse a ellos por riesgo de derrumbe.

Si restringimos la información al propio círculo, la nube de puntos está compuesta por 34 millones de puntos en una zona de $25 \mathrm{~m}$ de diámetro, logrando una gran densidad de puntos, oscilando entre 1 punto cada $3 \mathrm{~mm}$ hasta 1 punto cada $5 \mathrm{~mm}$.

Posteriormente, en el post-procesado de la información, se han unido en un solo modelo las nubes de puntos generadas desde varias posiciones. Para unir esas nubes con precisión hemos empleado unas dianas de control colocadas en el sitio, que en nuestro caso y con el software que disponemos (Cyclone de Leica), permite la combinación de las nubes con un margen de error mínimo (menor de $3 \mathrm{~mm}$ en la coincidencia de los centros de las dianas). Además, dentro del post procesado de la información, es necesario eliminar los puntos que están relacionados con elementos que no se corresponden con el objeto arqueológico, como por ejemplo la vegetación. En Cyclone, esta limpieza de la nube de puntos se hace a través de un proceso de depuración manual y controlada, con la cual se excluyen elementos que pueden llegar a distorsionar los resultados de representación. En la zona concreta del propio círculo ha sido necesario eliminar gran cantidad de puntos que se corresponden a vegetación puntual que, a pesar de estar recientemente rozado, se ha registrado en gran porcentaje. El objetivo ha sido evitar que ésta, con una cota superior a la del suelo o el elemento arqueológico, distorsionara el modelo digital del terreno. 
Hemos empleado otro software (3DReshaper) para realizar un modelo digital de detalle en base a la triangulación de la nube de puntos del círculo, que permite representar con detalle la forma del círculo lítico, incluso cada una de las piedras, como se puede ver en la siguiente imagen.

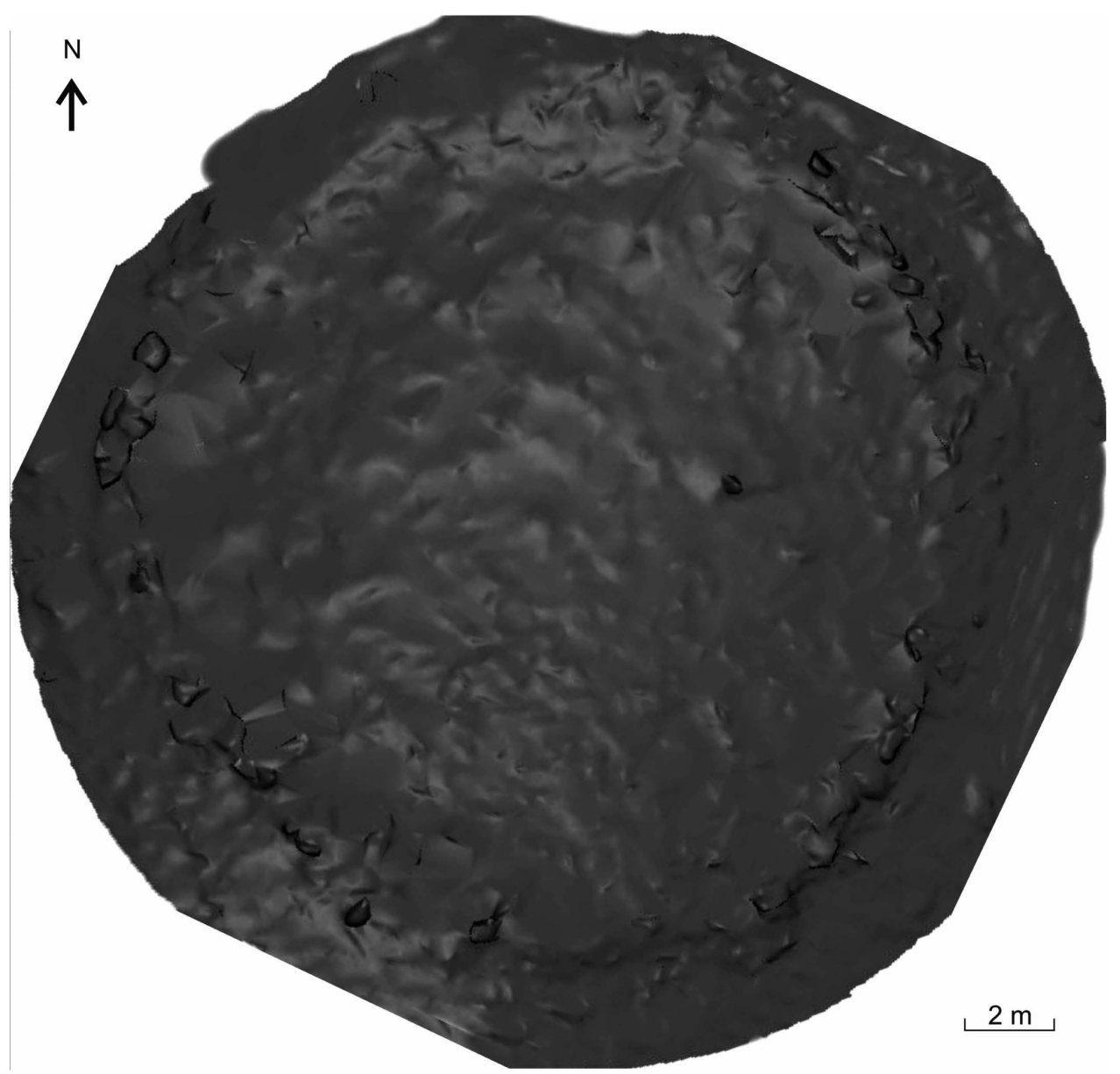

Figura 8. Modelo Digital de detalle del círculo lítico.

Resultados 


\section{CARACTERIZACIÓN MORFOLÓGICA.}

La documentación del círculo se realizó en el año 2008, durante el mes de agosto. A partir de los datos tomados se define una estructura de $20 \mathrm{~m}$ de diámetro, con una morfología circular bien determinada y homogénea. A pesar de ello, como veremos, presenta diferentes grados de conservación.

La apariencia general permite reconocer al círculo lítico como una estructura completamente cerrada. No obstante, existe una pequeña zona, en el NE, donde la densidad de piedras que componen la estructura disminuye, pero sin llegar a producirse una interrupción del círculo evidente. En el espacio interior definido por el círculo de piedras no se observa ninguna estructura, aunque sí están presentes numerosas piedras de pequeño y mediano tamaño. La superficie interior se encuentra ligeramente deprimida respecto al exterior de la misma.

El círculo presenta dos sectores diferenciados: la mitad S está formada por grandes bloques graníticos, alcanzando los más grandes una altura desde la superficie de entre 50 y $60 \mathrm{~cm}$. Sin embargo, en la mitad $\mathrm{N}$ asistimos a la presencia de piedras de menor tamaño con una disposición más horizontal.

Descendamos a una descripción más pormenorizada por cuadrantes:

En el cuadrante SW el anillo alcanza un ancho de entre 100 y $80 \mathrm{~cm}$, presentando grandes bloques hincados. El sector más ancho tiene alrededor de $1 \mathrm{~m}$, mientras que el más estrecho oscila entre los 40 y $50 \mathrm{~cm}$. Es en este sector $\mathrm{SW}$ donde mejor se define la estructura, encontrándose los bloques encajados entre sí. También está presente abundante mampostería de cachote. Es en este sector del círculo donde la estructura alcanza una mayor altura, rondando los $80 \mathrm{~cm}$ desde la superficie.

El cuadrante SE también está compuesto fundamentalmente por una estructura pétrea de piedra menuda con algún bloque de gran tamaño, encontrándose bien definido por mampostería de cachote. Este cuadrante es bastante homogéneo en lo que anchura se refiere. La altura es menor que la del cuadrante anterior, no sobrepasando los $40 \mathrm{~cm}$.

El cuadrante NE presenta algunas piedras hincadas con mampostería de cachote imbricada, lo que permite que la estructura se conserve bien definida en este sector. Como dijimos anteriormente, es en este sector donde parece existir la única posible interrupción de la estructura (al E), aunque con los datos disponibles, y a falta de una excavación que lo confirme, no estamos en condiciones de afirmar la existencia de dicha interrupción. La anchura de la estructura en este sector alcanza $1 \mathrm{~m}$ en su parte más ancha y ronda los $60 \mathrm{~cm}$ en la más estrecha. En lo que respecta a la altura, existen algunos tramos donde la estructura está formada por piedras hincadas que llegan a alcanzar entre 40 y $50 \mathrm{~cm}$. 

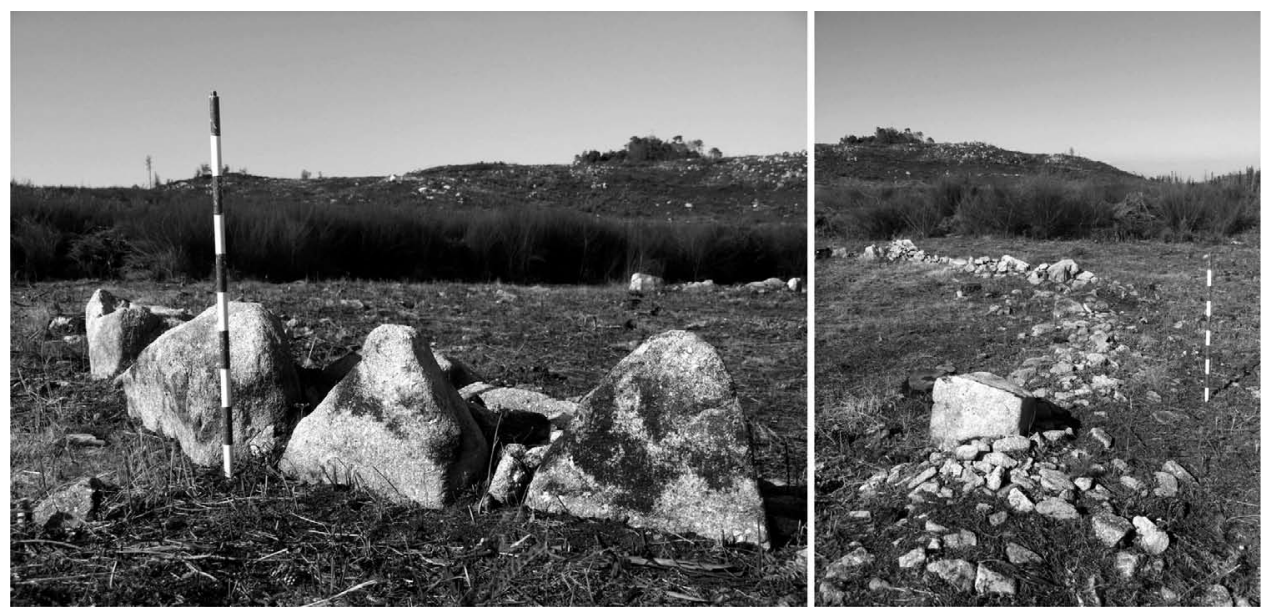

Figura 9. Detalles de la estructura pétrea que delimita el círculo. Imagen izquierda: piedras hincadas en el cuadrante SW. Derecha: mitad E con estructura de delimitación con mampostería de cachote.

Por último, el cuadrante N-NW es el que presenta unas características distintas a los anteriores. La estructura de delimitación del círculo se desdibuja, producto de una posible alteración. Pese a ello, continúan observándose piedras dispersas de pequeño tamaño uniformemente repartidas que permiten seguir adivinando la forma circular de la estructura, que alcanza un ancho aproximado de 2 metros y una altura no superior a $15 \mathrm{~cm}$ en este sector.

\section{ARCHIVO DIGITAL.}

El levantamiento topográfico de detalle con el Láser Escáner Terrestre constituye una fuente de información de gran valor, ya que a partir de ella se ha generado una base de datos digital sobre el yacimiento, que tiene numerosos ámbitos de aplicación. El resultado primordial y quizás el más importante es precisamente la obtención de un archivo digital, en el que se registran un gran número de medidas (34 millones de puntos) que definen la forma, tamaño, ubicación y superficie de cada elemento que lo compone en detalle. Además creemos que este archivo digital es fundamental en yacimientos que son especialmente sensibles y/o frágiles, como es el caso del círculo lítico de Monte Lobeira, que está formado por unas piedras de un tamaño medio, escasamente imbricadas, que fácilmente se invisibilizan bajo el tipo de cobertura vegetal habitual y con un alto riesgo de destrucción por causas fortuitas (por ejemplo, con el trabajo del área con maquinaria agrícola), por 
lo tanto, con un riesgo de alteración muy alto. Un factor que se suma a esta fragilidad física es el hecho de que estamos ante un tipo de yacimiento muy poco común (se conocen menos de una decena de círculos líticos en Galicia); su singularidad aumenta la necesidad de un registro de detalle y una salvaguarda más intensa, sea cual sea el tiempo histórico al que pertenezca.

Sobre esta base de millones de puntos, se pueden obtener diversos productos, como por ejemplo:

Registro en 3D del volumen del yacimiento y de su entorno inmediato, que, al estar georreferenciado, permite su vinculación con documentación espacial tomada con anterioridad y con posterioridad a este momento.

Representación precisa de estos volúmenes en planos técnicos en $2 \mathrm{D}$ y $3 \mathrm{D}$, posibilidad de hacer un dibujo de detalle "piedra a piedra", creación de superficies y modelados de la superficie y del terreno, microtopografías, etc.

Documentación y Archivo digital de calidad: la información recuperada mediante este tipo de registro se puede destinar como mecanismo de documentación y archivo que posibilita la preservación digital del elemento registrado. Este archivo digital es especialmente interesante en sitios sensibles o con riesgo de deformación, alteración, etc. ya que posibilita la preservación digital de un momento concreto del yacimiento. Además, cabe la posibilidad de su manipulación digital para obtener diverso material gráfico, mediciones e incluso la comparación con mediciones posteriores.

Reconstrucciones del sitio, incluso del terreno, abarcando tanto elementos arqueológicos o arquitectónicos como naturales, pudiendo emplearse esta documentación geométrica de alta densidad como base para crear modelos, representar su aspecto pasado e incluso plantear de una manera más visual la repercusión de planes de acción futuros.

Creación de infografías: se pueden emplear las nubes de puntos como base para la recreación o reconstrucción de la forma del sitio, simulación de escenas, para obtener imágenes, vídeos, paseos virtuales, etc., algo especialmente interesante para la presentación visual del elemento escaneado entre el público general.

También es posible usar estos datos para monitorizar la estructura arqueológica y comprobar sus cambios milimétricos con el paso del tiempo, aunque para esta opción tan especializada sería necesario establecer una serie de bases y referencias, que no fueron establecidas para este caso.

$\mathrm{Y}$ es que uno de los temas que se refleja en la literatura sobre este instrumento y su aplicación al campo patrimonial es que, frente a una captura de datos mucho más rápida que con otros métodos de medición directa, el manejo y tratamiento de estos datos es compleja y costosa en tiempo. Además, necesita unos programas 
especializados y un personal especializado también, buscándose soluciones desde distintas disciplinas para automatizar el procesado de la nube de puntos y obtención de diversos resultados (p.e. Lichti et al 2008; Roca-Pardiñas et al 2008). Dependiendo del tipo de producto que se quiera obtener, el tiempo de postprocesado varía, siendo lo más costoso, por nuestra experiencia, los dibujos de líneas tridimensionales de cada componente de una estructura, es decir, los dibujos "piedra a piedra"6.

\section{CARACTERIZACIÓN ARQUEOLÓGICA: FORMA Y FUNCIÓN.}

Un tema que emerge al tratar este tipo de yacimientos es su adscripción cronocultural. Hay registros, por ejemplo en el País Vasco, de estructuras tumulares de diferente adscripción que comparten emplazamiento y entre las que existe una estrecha similitud formal. Algunas de ellas se sabe claramente que son túmulos funerarios del Neolítico, mientras que otras son estructuras habitacionales medievales (Moraza et al 2003; Moraza y Mujika 2005).

La relación entre yacimientos de la Prehistoria Reciente y de época medieval en Galicia es habitual. Ejemplo de ello son los yacimientos de Montenegro (Gianotti y Cancela 2005), Carballeira do Espíritu Santo (Ballesteros y Blanco 2009), A Mourela (Bonilla y Fábregas 2009) y Os Remedios (Bonilla et al 2006; Fabregas et al 2007). Esta coincidencia reincidente permite plantear que el patrón de emplazamiento en ambos periodos deben tener ciertos condicionantes semejantes, ya que se reocupan en la Edad Media áreas explotadas en el Neolítico y en la Edad de Bronce. No obstante, para resolver uno de los principales problemas al que nos enfrentamos a la hora de abordar el estudio de este tipo de estructuras (la cronología) necesitamos de intervenciones arqueológicas y análisis de muestras que permitan datarlas, ya que sin disponer de dataciones absolutas siempre nos moveremos en el terreno de las hipótesis. Sin este tipo de datos, lo único que estamos en condiciones de constatar es la inmediatez de la estructura con los dos únicos túmulos presentes en el Monte Lobeira, túmulos con los que, por otra parte, el círculo se encuentra perfectamente alineado.

De hecho, fue la excavación arqueológica la que permitió determinar la cronología del que quizá es el círculo lítico más famoso de todo el NW peninsular. Nos referimos al conocido como círculo lítico grande de A Mourela o A Mourela 5, dado a conocer por F. Maciñeira (1929: 204-207) y excavado recientemente (Boni-

${ }^{6}$ Varios ejemplos de otros sitios documentados con este instrumento por nosotros, los resultados obtenidos y el tiempo necesario en cada fase de trabajo están descritos en Mañana-Borrazás et al 2009. 
lla y Fábregas 2009; Fábregas y Bonilla 2006) después de toda una serie de avatares. F. Maciñeira (1929) proponía como hipótesis que el círculo era coetáneo a los monumentos megalíticos ya que ambos se encontraban alineados. En esta excavación se pudo precisar la cronología de los restos de la estructura circular descrita por F. Maciñeira, situando su construcción entre el siglo VIII y el siglo XVI d.C (Bonilla y Fábregas 2009; Fábregas y Bonilla 2006: 187). No siendo estructuras del mismo período cronocultural, creemos que la monumentalidad de los túmulos ha debido de influir en la elección del emplazamiento de esta construcción medieval ya que se alinea con ella. Siendo los túmulos elementos que perduran en el tiempo, visibles y que han sido referentes en diversas épocas, como indica las habituales reutilizaciones que se identifican en varios monumentos megalíticos tras su construcción, es altamente probable que hayan ejercido como atractores culturales desde su creación hasta la actualidad.

En otros dos casos, la excavación arqueológica no solo ha sido necesaria para adscribir cronológicamente las estructuras circulares, sino que ha sido imprescindible para conocer su simple existencia. Nos referimos, por un lado, al círculo lítico de Montenegro en Moaña (Gianotti et al 2010), y por otro lado, al anillo lítico de Betote en Sarria (Cano 2008a, 2008b).

Para el primero disponemos de dataciones radiocarbónicas ya mencionadas al inicio del trabajo que permiten situar con claridad, algunos de los momentos constructivos y de uso del recinto circular de Montenegro en el entorno del 2800-2500 cal BC. Por otro lado, en el caso del anillo lítico de Betote contamos con una información fragmentaria y muy general publicada como informe de excavación (Cano 2008a). De todas formas, el autor documenta un anillo lítico periférico a un bolo granítico perteneciente a un yacimiento adscrito al período calcolítico, yacimiento que, en su conjunto, configuraría un espacio simbólico-ritual (Cano 2008a:179; Cano 2008b:165)

Finalmente, queremos resaltar el interés de aplicar un instrumento como el Láser Escáner Terrestre para obtener un registro digital, denso y de gran precisión del sitio, que permite representar de manera fidedigna su forma y estado en las fechas en las que se hizo el levantamiento. En el momento actual de desarrollo del instrumental y los programas para capturar y manejar estos datos, la gran virtud de este instrumento (su agilidad en campo, la densidad de captura, etc.) queda disminuida por la dificultad de extraer cierto tipo de resultados de ellos, que supone por lo general una gran carga de trabajo. En el caso que aquí presentamos, hemos obtenido unos resultados que creemos que son satisfactorios sin ser necesario mucho tiempo de post-procesado: las secciones y el MDT permiten una representación del sitio de gran riqueza y detalle. Con todo, lo que más destacamos es que hemos obte- 
nido un archivo digital denso, preciso y de calidad que permite una preservación digital del sitio y sobre el que se puede trabajar en el futuro y obtener, por ejemplo, una planta en la que esté representada cada piedra que conforma el círculo lítico.

\section{BIBLIOGRAFÍA}

ARIAS, P.; HERRÁEZ, J.; LORENZO, H.; ORDÓÑEZ, C. 2005: "Control of structural problems in cultural heritage monuments using close-range photogrammetry and computer methods", Computers and Structures, 83: 1754-66.

BALLESTEROS ARIAS, P.; BLANCO ROTEA, R. 2009: "Aldeas y espacios agrarios altomedievales en Galicia”, en J. A. Quirós Castillo (ed.), The Archaeology of Early Medieval Villages in Europe. Documentos de Arqueología e Historia, 1: 115-135. Bilbao.

BAS LÓPEZ, B. 1997: “Arquitectura para la producción campesina”, Galicia Antropología XXIII: 192-353.

BAS LÓPEZ, B. 2002: As construccións populares: un tema de etnografía en Galicia. Sada.

BONILLA RODRÍGUEZ, A.; CÉSAR VILA, M.; FÁBREGAS VALCARCE, R. 2006: "Nuevas perspectivas sobre el espacio doméstico en la Prehistoria reciente del NO: El poblado de Os Remedios (Moaña-Pontevedra)”, Zephyrus. Revista de prehistoria y arqueología, 59: 257-73.

BLOT, J. 1995: Contribution à l'étude des cercles de pierre en Pays Basque de France, Bulletin de la Société Préhistorique Française, 92 (4): 525-548.

BLOT, J., 1997. Círculos de piedras (o baratze) en el País Vasco Norte. Ensayo de sinthesis. Kobie, 24. 33-66. Bilbao.

BONILLA RODRÍGUEZ, A.; FÁBREGAS VALCARCE, R. (eds.),. 2009: Círculo de engaños: Excavación de A Mourela (As Pontes de García Rodríguez, A Coruña). Andavira Ed. Santiago Compostela.

BRADLEY, R. 1998: The significance of monuments on the shaping of human experience in Neolithic and Bronze Age Europe. Routledge. London.

BRADLEY, R.; BALL, C.; CROFT, S.; PHILLIPS, T. 2002: "The stone circles or Northeast Scotland in the light of excavation", Antiquity, 76: 840-48.

BURL, A. 2005: Prehistoric stone circles. Buckinghamshire, Shire publications. UK.

CALADO, M. 1997: Cromlechs alentejanos e arte megalítica, Brigantium, vol.10:289-297. A Coruña.

CALADO, M. 2004: Menires do Alentejo Central. Genese e evoluçao da paisagem megalítica regional, Tesis Doctoral, Universidade de Lisboa.

CANO PAN, J. 2008a: "Escavación do anel lítico periférico, extracción, traslado e posta en valor do bolo granítico con gravados, Betote, Sarria (Lugo)”, Actuacións arqueolóxicas 2006: 179-180.

CANO PAN, J. 2008b: "Intervención arqueolóxica en Betote, dentro das obras da autovía A-6, NadelaSarria (lugo)”, Actuacións arqueolóxicas 2006: 165-166. 
CRIADO BOADO, F. 1993: "Visibilidad e interpretación del registro arqueológico", Trabajos de Prehistoria, 50: 39-56.

DIEZ CASTILLO, A. 1996/97: Utilización de los recursos en la Marina y Montaña cantábricas: una prehistoria ecológica de los valles del Deva y Nansa. Illunzar, 3. Guernika: Agiri.

DIEZ CASTILLO, A. y RUÍZ COBO, J. 1995: “Cromlechs y círculos líticos de piedras: los datos del sector central de la cornisa cantábrica”, en Actas del XXII Congreso Nacional de Arqueología (Vigo, 1993), I: 47-53.

FÁBREGAS VALCARCE, R.; BONILLA RODRÍGUEZ, A. 2008: "Escavación arqueolóxica en área do GA15070128, A Mourela 5, As Pontes de García Rodríguez (A Coruña)", Actuacións arqueolóxicas 2006: 187-188.

FÁBREGAS VALCARCE, R.; BONILLA RODRÍGUEZ, A.; CÉSAR VILA, M. 2007: Monte dos Remedios (Moaña. Pontevedra). Un asentamiento de la Prehistoria Reciente. Tórculo Edicións. Santiago de Compostela.

FÁBREGAS VALCARCE, R.; VILASECO VÁZQUEZ, X.I. 2003: "El Neolítico y el megalitismo en Galicia: problemas teórico-metodológicos y estado de la cuestión”. En V. S. Gonçalves (ed.): Muitas antas, pouca gente? Origens, espaços e contextos do Megalitismo: 281-304. IPA. Lisboa.

FILGUEIRA VALVERDE, J.; GARCÍA ALÉN, A. 1956: "La carta arqueológica de la provincia de Pontevedra", El Museo de Pontevedra VIII: 31-210.

FILGUERA VALVERDE, J.; GARCÍA ALÉN, A. 1977: “Inventario de Monumentos Megalíticos”, El Museo de Pontevedra XXXI: 51-130.

GIANOTTI GARCÍA, C.; CANCELA CEREIJO, C. 2005: “Neolítico Final: Montenegro. Testemuña da ocupación humana durante o Neolítico Final e o período Alto-Medieval na Península do Morrazo". En F. Criado Boado, F.; y E. Cabrejas Domínguez (coord.):. Obras Públicas e Patrimonio: Estudo Arqueolóxico do Corredor do Morrazo. TAPA (Traballos de Arqueoloxía e Patrimonio), 35: 50-54. Santiago de Compostela: IEGPS, CSIC.

GIANOTTI GARCÍA, C.; MAÑANA BORRAZÁS, P.; CRIADO BOADO, F. 2010 (e.p.): "Montenegro, a Neolithic enclosure in Galicia. Insights into Megalithic space". En A. Cruz et al (ed.) Early farmers landscapes. XV UISPP (Lisboa, september 2006). BAR.

GIBSON, A. 2005: Stonehenge and Timber Circles. Tempus Publishing, Gloucestershire.

GROGAN, E. y ROCHE H. 2002: "Irish Palisade Enclosures". En Gibson, A., (ed.): Behind Wooden Walls: Neolithic Palisaded Enclosures in Europe. Archaeological Reports International Ser. 1013. Archaeopress. Oxford.

HARTWELL, B. 2002: "A neolithic ceremonial timber complex at Ballynahatty Co.Down”, Antiquity, 76 (292): 526-32.

LAMBERS, K.; EISENBEISS, H.; SAUERBIER, M.; KUPFERSCHMIDT, D.; GAISECKER, T.; SOTOODEH, S.; HANUSCH, T. 2007: "Combining photogrammetry and laser scanning for the recording and modelling of the Late Intermediate Period site of Pinchango Alto, Palpa, Peru.", ISPRS Journal of Archaeological Science, 34 (10): 1702-1712.

LICHTI, D.; PFEIFER, N.; MAAS, H-G. (eds.). 2008: "Theme issue Terrestrial Laser Scanning". Journal of Photogrammetry and Remote Sensing, 63 (1). 
LÓPEZ CUEVILLAS, F. 1959: "La época megalítica en el Noroeste de la Península”, Caesaraugusta, 13-14: 21-77.

LÓPEZ CUEVILLAS, F. y BOUZA BREY, F. 1931: "La civilización neoeneolítica gallega", Archivo Español de Arte y Arqueología, 19.

MACIÑEIRA, F., 2002 [1947]: BARES. Puertos Hispánicos de la Primitiva Navegación Occidental. Edita CSIC y Fundación Ortegalia, 427 págs. Santiago de Compostela.

MACIÑEIRA Y PARDO DE LAMA, F. 1929: "Notable grupo de círculos líticos y túmulos de la cuenca superior del Eume", Arquivo do Seminario de Estudos Galegos 2: 198-230.

MAÑANA-BORRAZÁS, P.; BLANCO ROTEA, R.; RODRÍGUEZ PAZ, A. 2009: "La documentación geométrica de elementos patrimoniales con Láser Escáner Terrestre. La experiencia del LaPa en Galicia", Cuadernos de Estudios Gallegos, 122: 33-65.

MARAMBIO, A.; GARCÍA ALMIRALL, P. 2006: "Escáner láser: modelo 3d y orto imágenes arquitectónicas de la iglesia de Santa María del Mar en Barcelona", ACE: architecture, city and environment, 2: 178-187.

MARIÑO FERRO, X. R. 2000: Antropoloxía de Galicia. Vigo.

MARTÍNEZ MURGUÍA, M. 1901 [1865]: Historia de Galicia. 2º edición. A Coruña

MONSERRAT, O.; CROSETTO, M. 2008: "Deformation measurement using terrestrial laser scanning data and least squares 3D surface matching", ISPRS Journal of Photogrammetry and Remote Sensing, 63 (1): 142-154.

MONTEAGUdO GARCÍA, L. 2003: "Menhires y marcos de Portugal y Galicia”, Anuario Brigantino, 26: 25-50.

MORAZA BAREA, A.; MUJIKA ALUSTIZA, J. A. 2005: "Establecimientos de habitación al aire libre. Los fondos de cabana de morfología tumular: características, proceso de formación y cronología". Veleia, 22: 77-110, Vitoria.

MORAZA BAREA, A.; MORO DEORDAL, I.; MUJIKA ALUSTIZA, J. A., 2003: "Contribución al estudio de las estructuras tumulares en Arqueología: entre la similitud morfológica y la disparidad de funciones", Veleia 20, Vitoria.

OBERMAIER, H. 1923: "Impresiones de un viaje prehistórico por Galicia", Boletín Arqueológico de la Comisión Provincial de Monumentos Históricos y Artísticos de Ourense, Tomo VII, 148: $1-21$.

OREJAS, A. 1995: "Del marco geográfico a la Arqueología del Paisaje. La aportación de la fotografía aérea". Consejo Superior de Investigaciones Científicas. Madrid.

PEÑALVER, X. 2005: "Los crómlech pirenaicos, Bolskan: Revista de arqueología del Instituto de Estudios Altoaragoneses", $\mathrm{N}^{\circ} 22: 11-349$.

PEÑALVER, X. 2001: "El Bronce Final y la Edad del Hierro en la Euskal Herria atlántica: cromlechs y castros". Complutum 2001: 51-71.

SARALEGUI Y MEDINA, L. 1867: Estudios sobre la época céltica en Galicia. Ferrol.

SARALEGUI Y MEDINA, M. 1918: Los monumentos megalíticos de España. Madrid. 
SILVA, F.A.P. 1997: Problemática em torno do Megalitismo do Centro-Norte litoral de Portugal. En Rodríguez Casal, A. (ed.). O Neolítico Atlántico e as orixes do Megalitismo: Actas do Coloquio Internacional (Santiago de Compostela, abril 1996): 635-56. USC, Santiago de Compostela.

SCHULZ, T.; INGENSAND, H. 2005: "El escaneado por láser terrestre: investigaciones y aplicaciones del escaneado de alta precisión", Topografía y cartografía: Revista del Ilustre Colegio Oficial de Ingenieros Técnicos en Topografía, 22 (131): 3-12.

VILASECO VÁZQUEZ, I. 2009: “O círculo que foi. A Mourela no seu contexto histórico”, en A. Bonilla Rodríguez y R. Fábregas Valcarce (eds.). Círculo de egaños: Excavación de A Mourela (As Pontes de García Rodríguez, A Coruña): 37-58.

VILLOCH VÁZQUEZ, V. 1998. "Menhires y losas antropomorfas en Galicia”, en Actas do Colóquio "A Pré-História na Beira Interior" (Tondela, Nov. 1997): 175-87. Cámara Municipal de Sabrosa, Viseu.

VIQUEIRA BARRIO, V. 1960: El Castrum Lupariae. Vilagarcía.

YASTIKLI, N. 2007: "Documentation of cultural heritage using digital photogrammetry and laser scanning", Journal of Cultural Heritage, 8 (4): 423 - 427.

Más información sobre las publicaciones de los autores del Laboratorio de Patrimonio (CSIC) en el Repositorio Institucional de CSIC de acceso abierto: DIGITAL CSIC http://digital.csic.es/

\section{Agradecimientos}

Queremos expresar nuestro más sincero agradecimiento a todas las personas que componen la Comunidad de Montes de András (Vilanova de Arousa, Pontevedra), cuya amabilidad y hospitalidad fueron las principales inspiradoras de este trabajo. También a Güimil por su colaboración en la elaboración de las figuras y a David por la lectura del trabajo. 